\title{
Pegylated liposomal doxorubicin in ovarian cancer
}

This article was published in the following Dove Press journal:

Therapeutics and Clinical Risk Management

7 August 2009

Number of times this article has been viewed

\section{Robert Strother ${ }^{1,2}$}

Daniela Matei ${ }^{1-5}$

'Department of Medicine, ${ }^{2}$ Indiana University Melvin and Bren Simon

Cancer Center, ${ }^{3}$ Department of Obstetrics and Gynecology, ${ }^{4}$ Department of Biochemistry and Molecular Biology, ${ }^{5} \mathrm{VA}$ Roudebush Hospital Indiana University School of Medicine, 535 Barnhill Drive, Indianapolis, IN, 46202
Correspondence: Robert Strother Indiana University Simon Cancer Center 535 Barnhill Drive, RT 473, Indianapolis, IN, 46202, USA

Tel + I (3I7) 2780070

Fax + I (3I7) 2780074

Email rstrothe@iupui.edu
Abstract: The encapsulation of doxorubicin in a pegylated liposomal matrix led to a reformulated agent with a different toxicity profile and improved clinical utility. Liposomal doxorubicin is devoid of the cardiac toxicity associated with doxorubicin, but is associated with predictable muco-cutaneous toxicity. The liposomal formulation leads to improved delivery to the target tumor tissue, allowing enhanced uptake by cancer cells. These properties translate into clinical utility in recurrent ovarian cancer as demonstrated by phase II and III trials, this proven clinical efficacy leading to FDA approval in second-line therapy for ovarian cancer. New combinations with cytotoxics, in particular with carboplatin, have demonstrated an acceptable toxicity profile and clinical utility in platinum-sensitive ovarian cancer. A favorable toxicity profile renders liposomal doxorubicin an ideal partner for combination regimens with other cytotoxics, and more recently with biological agents. Such combinations are the subject of ongoing clinical trials.

Keywords: ovarian cancer, doxorubicin, liposomes, pegylated liposomal doxorubicin

\section{Introduction}

The pivotal phase III trial of pegylated liposomal doxorubicin (PLD) in ovarian cancer published in 2001 confirmed the activity of this drug in second-line metastatic ovarian cancer (OC), demonstrating equivalent overall survival (OS) compared with topotecan in women with recurrent platinum-sensitive and resistant OC. ${ }^{1}$ A nearly 40 -week advantage in OS over topotecan was noted in a planned subset analysis for patients with platinum-sensitive OC, indicating marked clinical efficacy in this subgroup. PLD toxicities included bone marrow suppression, mucositis, and extensive palmar-plantar erythrodysesthesia (PPE), or hand-foot syndrome, incidence of the latter approaching $50 \%$. Other reports note that PPE is not always limited to the hands and feet, but at times it results in diffuse skin involvement. ${ }^{2}$ However, safety studies have continued to show that the cumulative myocardial toxicity associated with doxorubicin (DOX) is avoided with the use of PLD. ${ }^{3}$

PLD serves as a prototype for the role of formulation in defining the clinical utility of chemotherapeutics, the reformulation of DOX in a pegylated liposomal matrix having increased its clinical utility, and abrogated some of its toxicities. However, while some of the adverse events typically associated with DOX are avoided by using the liposomal encapsulation, new and unique toxicities arise with PLD. This has been highlighted in reports of toxicities from phase II and III trials as well as in case reports and series. PLD avoids the cardiac toxicity typically associated with DOX, but has 
well documented and predictable cutaneous toxicity. This review will provide a brief overview of the development and relevant clinical pharmacology of PLD, but will primarily focus on its clinical use in OC and the adverse events associated with this use.

\section{A brief history of development}

Liposomes are phospholipid bilayers engineered to form a vesicle or "nano-package". The concept of liposomal encapsulation for drug delivery was originally proposed in the 1980 s as a method to change the pharmacological properties of drugs, attempting to improve targeting to the tissue of interest, as well as to avoid toxicities. ${ }^{4}$ It was originally thought that this technology would offer a number of advantages. Longer exposure in vivo would result from protection of the active compound from metabolism and excretion. More targeted therapy would result from endocytosis of the active compounds at the site of action, thereby limiting exposure to nontarget tissues. This in turn would lead to minimization of off-target toxicity, as a result of the drug being delivered primarily to the tissue of interest. These advantages were, and remain, particularly appealing for drugs that have narrow therapeutic indices, severe toxicities, and/or are unstable in vivo. The reformulation of drugs in liposomes is still an active area of pharmaceutical development, as is the engineering of optimal liposomes.

Chemotherapeutics were appealing from the outset for liposomal encapsulation as a pharmacologically active set of compounds with many off-target toxicities. ${ }^{5,6} \mathrm{DOX}$, an anthracycline active in a broad variety of tumors but with a life-time cumulative dose cardiotoxicity, was an early candidate drug explored for this new formulation. ${ }^{7}$ The in vitro development of the liposomal carrier for DOX encountered several hurdles in early development related to stability of the matrix. Unstable formulations resulted in drug leakage; on the opposite extreme, matrices too avid for the active compound prevented its release at the intended site of action. ${ }^{8,9}$

Different formulations of liposomes, and/or addition of various compounds to liposomes, impart differing properties to the end-products. To evade rapid recognition and uptake by the reticular-endothelial system, liposomes were engineered by adding a polyethylene glycol hydrophilic polymer layer, or PEG. ${ }^{10}$ The final compounds are referred to as pegylated, sterically stabilized, or STEALTH liposomes. These pegylated liposomes display reduced rates of uptake by the liver and remain in circulation for longer periods compared to conventional liposomes. The physio-chemical properties and manufacturing process for the commercially available formulations of PLD were excellently reviewed by Gabizon. ${ }^{11}$

\section{Pharmacokinetic properties}

Preclinical work in cancer mouse models offered insight into the pharmacokinetic and pharmacodynamic changes conferred by the pegylated liposomal encapsulation to DOX. Early work indicated improved targeting of the compound to tumors, allowing enhanced uptake by cancer cells, and increased extravasation at the tumor site, but these properties were not reported consistently. ${ }^{12-14}$ An important finding was that the liposomal encapsulation of the drug resulted in increased DOX exposure, measured as the total area under the curve (AUC). In one report the AUC for liposomal DOX (not pegylated) and for PLD were 2.6- and 6.8-fold higher than for DOX. This change likely arose from a progressive decrease in half-life in plasma from $23.7 \pm 5$ hours for DOX, to $26 \pm 3$ and $46 \pm 14$ hours for liposomal DOX and PLD, respectively. ${ }^{15}$

One of the major reasons for exploring liposomal encapsulation of chemotherapeutics in general, and DOX in particular, was to change the pharmacokinetic properties of the drug, the concept being that encapsulation in a liposome would allow greater exposure of the target to the drug. Early human studies supported this idea, with the early studies showing a nearly 300-fold increase in AUC for liposomal doxorubicin compared to the free drug. ${ }^{16}$ Modifications of the liposomes' formulation affects their pharmacokinetic properties, specifically the release rate of the active compound from the liposome, and the rate at which the liposome is cleared. ${ }^{17,18}$ Free DOX has a reported clearance of approximately $50 \mathrm{~L} / \mathrm{h}$, with a volume of distribution of approximately 9 L. ${ }^{19,20}$ By comparison, for the dosing range of 40 to $60 \mathrm{mg} / \mathrm{m}^{2}$, PLD has a reported clearance of 0.02 to $0.07 \mathrm{~L} / \mathrm{h} / 1.7 \mathrm{~m}^{2}$ and a volume of distribution 2 to $10 \mathrm{~L} / \mathrm{m}^{2}{ }^{11}$

Scarce information is available on pharmacokinetic properties of PLD in special populations. While no studies to date have explored PLD disposition in the elderly, the effects of age and end-organ dysfunction were explored in a study in which 29 patients with chronic renal insufficiency $(<90 \mathrm{~mL} / \mathrm{min}$ ) were treated with PLD. Because the median age in this study was 70 years, the influence of age was indirectly addressed. The study reported a slight, but not statistically significant increase in adverse events in the elderly, and a significantly increased need for dose reductions in patients with impaired renal function. ${ }^{21}$

For repeated administration, preclinical experiments in rat models have shown that the clearance of PLD is increased 
after repeated dosing; however the mechanism for this was not determined. ${ }^{22}$ In humans, the opposite occurs; repeated dosing results in a decline in PLD clearance between the first and third cycles. ${ }^{23}$ This becomes relevant in that repeat administration of PLD may result in increased exposure to the drug, and hence, increased toxicity as its clearance declines with each cycle.

Few reports demonstrated sequence-dependence in the disposition of agents administered in combination with PLD, suggesting a potential for drug-drug interactions. For instance, the administration of PLD with vinorelbine led to a sequence-dependent change in vinorelbine distribution. If PLD was given first, the exposure to vinorelbine increased compared to the reverse sequence. The authors postulated that PLD may act as a p-glycoprotein (MDR1) inhibitor, thus reducing the excretion of vinorelbine. ${ }^{24}$

\section{Phase I and II development of PLD}

Initial studies of a liposomal encapsulation of DOX were reported by a group from the Royal Liverpool Hospital. They administered liposome-encapsulated DOX to 6 patients with hepatic metastases from gastrointestinal adenocarcinomas and recorded one objective response and absence of the typical doxorubicin induced toxicity. ${ }^{25}$ This led to several phase I trials which found that the dose of a liposomeencapsulated doxorubicin could be driven up significantly higher compared to free DOX. ${ }^{26}$ The maximal dose reached with this formulation was $120 \mathrm{mg} / \mathrm{m}^{2}$ given every 3 weeks; however this was associated with substantial bone-marrow suppression, particularly neutropenia, as well as stomatitis and alopecia. ${ }^{27}$

After early indicators of success in gynecologic malignancies, a phase II study evaluated PLD in ovarian cancer. ${ }^{28-30}$ Forty-eight patients with OC, previously treated with paclitaxel and platinum, were treated with PLD administered at a dose of $50 \mathrm{mg} / \mathrm{m}^{2}$ every 28 days. The objective response rate (RR) in this trial was $19 \%$, and toxicities consisted of neutropenia, thrombocytopenia, and stomatitis. ${ }^{29}$

Interestingly, while it has been shown that PLD has linear dosing when administered in the range of $30-60 \mathrm{mg} / \mathrm{m}^{2}$, ie, increases in dose correspond to increased exposure in vivo, it has been also shown that a reduction in the dose of PLD reduces toxicity, but has no adverse effect on response. Much of the original work dosed PLD at $50 \mathrm{mg} / \mathrm{m}^{2}$; however, retrospective analyses, followed by prospective validation, showed that the dose could be reduced to $40 \mathrm{mg} / \mathrm{m}^{2}$ without loss of efficacy but with reductions in the incidence of adverse events. A retrospective analysis of patients treated with PLD between 1997 and 1998 at 40 mg/m² every 28 days revealed a pattern of activity similar to what is expected at the higher dose of $50 \mathrm{mg} / \mathrm{m}^{2}$, but with reduced toxicities. ${ }^{31}$ Of 72 patients treated, $27 \%$ had objective responses, while grade 3-4 hematologic toxicities occurred only in a minority of patients: 1 case of neutropenia, 1 case of thrombocytopenia, and 8 cases of anemia. ${ }^{31}$ Mucositis and PPE were observed in 3 and 6 patients, respectively. A second retrospective analysis supported these findings, and confirmed marked decreases in skin toxicity with reduced PLD dosing. ${ }^{31,32}$ This led to a phase II study performed through the Gynecologic Oncology Group (GOG) testing the activity and toxicity of PLD at $40 \mathrm{mg} / \mathrm{m}^{2}$ in women with mixed gynecologic tumors. This study reported that women treated at this lower dose had similar response rates, but reduced toxicity compared to historical controls treated with the higher PLD dose ${ }^{33}$. The reported rate of PPE was $18 \%$, but no patients suffered from grade 3-4 hand-foot syndrome and only $8 \%$ of patients developed mucositis, none of which was grade 3-4. These observations formed the basis for the lower dose selection in future phase III trials testing PLD, including the Multicentre Italian Trials in Ovarian Cancer Group (MITO-3) trial discussed below. Likewise, biweekly administration of PLD at a dose of $20 \mathrm{mg} / \mathrm{m}^{2}$ led to reduced cutaneous toxicity, while retaining efficacy in relapsed ovarian cancer. Two phase II trials testing this schedule of administration reported grade $3 \mathrm{PPE}$ in less than $5 \%$ of patients and preserved clinical activity. ${ }^{34,35}$ A randomized comparison against the standard PLD dose has not been performed.

The fundamental markers for clinical activity in oncology trials are objective RR and/or survival. However, surrogate markers are sometimes pursued as a method for early insight into determining response. A commonly followed biomarker in ovarian cancer trials is CA-125, a glycoprotein secreted by cancer cells. ${ }^{36}$ The relationship between the efficacy of PLD and CA-125 concentration changes has been extensively explored. Interestingly, several studies have supported the idea that the response of CA-125 in patients receiving PLD may be delayed by as many as 3 cycles of therapy. In a retrospective analysis of 59 women who received PLD, it was observed that treatment discontinuation for increases in CA-125 were common. However, in those women who had a clinical response, CA-125 declines were not noted until cycle 3 or later. ${ }^{37}$ Another study of 239 women treated with PLD also found that early variance in CA-125 levels did not correlate with clinical benefit, as up to $10 \%$ of responders displayed increases in CA-125 concentrations of up to $25 \%$ during the first several cycles. ${ }^{38}$ However, in a trial of 120 women who 
had received either topotecan or PLD, consecutive increases in CA-125 across multiple cycles correlated with a decreased likelihood of response and all 54 responders had decreased CA-125 levels by the second cycle. ${ }^{39}$ These observations indicate that early variations in CA125 levels in patients treated with PLD should be interpreted within the context of clinical and radiographic findings for each case.

\section{Phase III trials}

Prior to the FDA-approval of PLD for recurrent OC, the accepted standards for second-line treatment of recurrent ovarian cancer included topotecan and paclitaxel. Response rates to these second-line agents ranged between 19\% and $29 \%$ for platinum-sensitive OC and $12 \%$ to $14 \%$ for women with platinum refractory OC..$^{40,41}$ The testing and introduction of PLD set a new standard, particularly in terms of durability of response, as response rates to PLD were not markedly dissimilar from those of older single agent regimens investigated in this setting.

The pivotal phase III trial reported by Gordon compared PLD to topotecan in women with recurrent OC. ${ }^{1}$ Patients were stratified based on platinum resistance (disease progression within 6 months of platinum-containing regimen) and bulkiness of disease (tumor mass $>5 \mathrm{~cm}$ ). Between May 1997 and March 1999, 481 patients were enrolled on this trial. Seven patients never received drug after enrollment; therefore 474 were analyzed, 235 on the topotecan arm, and 239 on the PLD arm. Percentages of patients with platinum-resistant OC and bulky disease were similar between arms. The topotecan arm included $47 \%$ patients with bulky disease and 53\% with platinum-resistant OC, and the PLD arm included $46 \%$ and $54 \%$ in these respective categories. Evaluation of OS, as the primary endpoint of the study, found no significant differences between the study arms. The OS on the PLD arm was 60 weeks, not significantly improved over the topotecan arm 56.7 weeks. However, in a planned subset analysis, there was a significant difference between the two arms for patients with platinum-sensitive OC. In this patient population, the OS of patients treated with PLD was 108 weeks, compared to 71.1 weeks for women treated with topotecan $(P=0.008)$, suggesting an increased benefit of PLD in this subgroup of patients.

A 4-year follow-up of this trial revealed long-term survival advantage for the PLD arm, regardless of the platinum-resistance status. ${ }^{40}$ Patients who had received PLD had an OS of 62.6 weeks compared to 59.7 weeks for those patients who had received topotecan $(P=0.05)$. This follow-up emphasized further the benefits of PLD in patients with platinum-sensitive OC, with an OS of 107.9 weeks in this group as compared to 70.1 weeks for patients treated with topotecan $(P=0.017)$. Further analysis of prognostic variables (age, performance status at enrollment, bulkiness of disease) found no other significant predictors of clinical benefit. Adverse events were common, with essentially all patients reporting toxicities. However, overall grade 4 events were more common in the topotecan arm (71\% vs $17 \%)$. The most common PLD toxicities included PPE (49\%) and stomatitis $(40 \%)$. The results of this study led to the FDA-approval of PLD for the second-line treatment of recurrent OC.

PLD has been subsequently compared to gemcitabine in 2 randomized phase III trials. In the trial reported by Mutch, patients with recurrent $\mathrm{OC}$, fallopian tube, or peritoneal cancer who had received at least 1 , but no more than 2 prior lines of therapy, including a platinum-based regimen, were randomized to either gemcitabine at $1000 \mathrm{mg} / \mathrm{m}^{2}$ on days 1 and 8 on a 21-day cycle, or to PLD at $50 \mathrm{mg} / \mathrm{m}^{2}$ day 1 on a 28-day cycle. ${ }^{41}$ From 2002 to 2004, 194 women were enrolled on this trial, 99 on the gemcitabine, and 96 on the PLD arm. The arms of the trial were well balanced on disease burden, performance status, platinum responsiveness, and prior exposure to taxanes. There were no statistical differences between the two arms for median OS (12.5 vs 13.5 months, $P=0.99$ ) or progression-free survival (PFS, 3.6 vs 3.1 months, $P=0.87$ ).

Toxicity assessment revealed toxicities specific to each arm. Gemcitabine's common toxicities included constipation, fatigue, nausea/vomiting, and neutropenia. PLD's common toxicities were fatigue, mucositis, and neutropenia. Among grade 3-4 toxicities on either arm, neutropenia was more common in gemcitabine-treated patients (38 vs 18 patients, $P=0.003)$, and PPE and mucositis were more common for those on PLD (10 vs 0 patients, and 3 vs 1 patients, respectively). Interestingly, as this trial allowed crossover at progression, 13 of the 66 women who crossed over from PLD to gemcitabine developed grade 2-3 PPE. This phenomenon likely represented a late toxicity of PLD, given that most of these cases occurred early after crossover (on day 1 of gemcitabine). ${ }^{41}$

Another trial comparing PLD to gemcitabine was MITO-3. ${ }^{42}$ The design of MITO-3 was similar to the study presented by Mutch, except for a different PLD dose (40 mg/ $\mathrm{m}^{2}$, as opposed to $50 \mathrm{mg} / \mathrm{m}^{2}$ ) and restriction of prior therapy to 1 regimen. Cross-over was not allowed, and assessment of response was based on RECIST. ${ }^{43}$ Treatment regimens were PLD at $40 \mathrm{mg} / \mathrm{m}^{2}$ day 1 on a 28-day cycle, and gemcitabine at $1000 \mathrm{mg} / \mathrm{m}^{2}$ given on day 1,8 , and 15 on a 28 -day cycle. 
One hundred and fifty-three patients were enrolled, with 77 randomized to gemcitabine and 76 randomized to PLD. The primary endpoint of the study was time to progression (TTP), and secondary endpoints included OS, safety, quality of life, and RR. Patients were well matched for age, stage of disease and, histological subtypes. A slightly higher number of patients with suboptimal debulking were enrolled in the gemcitabine arm (54 vs 49), and the median CA-125 concentration on enrollment was higher in the gemcitabine arm (243 vs $165 \mathrm{U} / \mathrm{mL}$ ). Patients on both arms received a median of 4 cycles of therapy. The objective RR was higher for gemcitabine ( $29 \%$ vs $16 \%$ ), TTP favored gemcitabine (20 vs 16 weeks), and the duration of response was equivalent between arms (18 weeks). However, OS assessment favored PLD (56 vs 51 weeks, $P=0.048$ ), with the curves between the two arms separating out at approximately 48 weeks.

Toxicities were roughly equivalent, with increased neutropenia for gemcitabine (6\% for PLD vs $23 \%$ for gemcitabine) and increased PPE for PLD (5\% for PLD vs $0 \%$ for gemcitabine). Quality-of-life (QoL) assessments performed on $79 \%$ of patients, at baseline and prior to each cycle of therapy, revealed equivalence at the 1 st and 4 th time-points, but superior QoL in PLD-treated patients at cycles 2 and 3 $(P<0.05)$. This may reflect better tolerance of PLD as overall toxicity on the PLD arm occurred in less than $10 \%$ of enrolled patients. Table 1 summarizes clinical outcomes and Table 2 summaries toxicities in phase III trials testing PLD administered as single agent. These trials have consolidated the role of PLD as preferred therapy for recurrent OC and positioned it as the standard for testing of new agents in this setting. Indeed, PLD has been used as the comparator arm in other phase III trials testing new single-agent chemotherapeutics, such as canfosfamide and patupillone in women with recurrent OC (unpublished results).

\section{PLD toxicity profile}

PLD has a different toxicity profile compared to the anthracycline base. The toxicities of the parent drug included the commonly observed hematologic and mucous membrane toxicities associated with most chemotherapeutics, as well as the unique and life-time dose-limiting cardiac toxicity at doses above 450 to $500 \mathrm{mg} / \mathrm{m}^{2} .{ }^{44}$ It was this unique toxicity that drove much of the initial safety assessment of PLD. Importantly, thorough early investigations including endomyocardial biopsies found no evidence of cardiac damage with PLD. ${ }^{45}$ Safety was further confirmed for prolonged PLD administration, no evidence of cardiac damage being observed when PLD was administered for more than 6 cycles. ${ }^{3}$ Finally, in a study with longer follow up, 14 patients exposed to a median life-time dose of $685.5 \mathrm{mg} / \mathrm{m}^{2}$ did not develop cardiac dysfunction by echocardiogram, nor developed symptomatic congestive heart failure. ${ }^{46}$ While not definitive, and in need of confirmation in a larger study population, it does appear that the cardiac toxicities associated with free DOX

Table I Phase III trials with pegylated liposomal doxorubicin (PLD) for recurrent/refractory ovarian cancer (OC)

\begin{tabular}{|c|c|c|c|c|c|c|}
\hline Author & Trial details & Arms & Eligibility & Outcomes & & \\
\hline \multirow[t]{8}{*}{ Gordon et al 2001' } & \multirow{8}{*}{$\begin{array}{l}\text { Randomized } \\
\text { Multi-center } \\
\text { Open-label } \\
\text { Second line }\end{array}$} & \multirow{4}{*}{$\begin{array}{l}\text { Topo } 1.5 \mathrm{mg} / \mathrm{m}^{2} / \text { day } \times \\
5 \text { days }\end{array}$} & \multirow{4}{*}{$\begin{array}{l}\text { Recurrence after } \\
\text { platinum based therapy } \\
\text { No prior exposure to } \\
\text { either agent }\end{array}$} & $N=474$ & & \\
\hline & & & & & Topo (235) & PLD (239) \\
\hline & & & & Median PFS (weeks) & 17 & 16.1 \\
\hline & & & & Median OS (weeks) & 56.7 & 60 \\
\hline & & \multirow{4}{*}{$\begin{array}{l}\text { PLD } 50 \mathrm{mg} / \mathrm{m}^{2} \\
\text { day I every } 28 \text { days }\end{array}$} & & Platinum-sensitive & 23.3 & 28.9 \\
\hline & & & & Median PFSª (weeks) & & \\
\hline & & & & Platinum-sensitive & 71.1 & 108 \\
\hline & & & & Median OS ${ }^{\mathrm{b}}$ (weeks) & & \\
\hline \multirow[t]{4}{*}{ Mutch et al $2007^{41}$} & Randomized & PLD 50 mg/m² & Recurrence after first-line & & $N=195$ & \\
\hline & Multi-center & day I every 28 days & Platinum based therapy & & Gem (99) & PLD(96) \\
\hline & $\begin{array}{l}\text { Second line } \\
\text { Allowed cross over }\end{array}$ & Gem $1000 \mathrm{mg} / \mathrm{m}^{2}$ & No prior exposure to & Median PFS (months) & 3.6 & 3.1 \\
\hline & at progression & days I and 8 & & Median OS (months) & 12.7 & 13.5 \\
\hline \multirow[t]{4}{*}{ Ferrandina et al $2008^{42}$} & Randomized & Gem 1000 mg/m² & Recurrence within & & $N=153$ & \\
\hline & Multi-center & days $I, 8$, and 15 & I 2 months after $\mathrm{CT}$ & & Gem (77) & PLD (76) \\
\hline & \multirow[t]{2}{*}{ Second line } & \multirow{2}{*}{$\begin{array}{l}\text { PLD } 40 \mathrm{mg} / \mathrm{m}^{2} \text { every } \\
28 \text { days }\end{array}$} & \multirow{2}{*}{$\begin{array}{l}\text { No prior exposure to } \\
\text { either agent }\end{array}$} & Median PFS (weeks) & 20 & 16 \\
\hline & & & & Median OS (weeks) ${ }^{c}$ & 51 & 56 \\
\hline
\end{tabular}

${ }^{\mathrm{a} P}=0.037,{ }^{\mathrm{b}} P=0.008,{ }^{\mathrm{c} P}=0.048$, all other results not significant.

Abbreviations: Gem, gemcitabine; Topo, topotecan; OS, overall survival; PFS, progression-free survival. 
are not shared by PLD. Importantly, cardiac toxicity has not emerged during investigation of PLD in phase III trials, ${ }^{40,41,47}$ but these trials limited the amount of PLD delivered to a maximum of 6 cycles.

Toxicities relatively unique to PLD include mucocutaneous toxicities, the most prominent being PPE or hand-foot syndrome. Rarely reported with DOX, the incidence and severity of PPE is much greater with the use of PLD. Erythema and pain to the palms and/or soles can progress to desquamation reminiscent of burns. This is thought to be related to prolonged exposure generated by PLD compared to DOX, which is cleared more rapidly. ${ }^{48,49}$ The extreme form of this syndrome includes diffuse skin involvement, a syndrome referred to as diffuse toxic erythema. ${ }^{2}$ Based on phase III trial reports, the incidence of PPE ranges from $10 \%$ in the trial reported by Mutch to $50 \%$ in the pivotal phase III trial. ${ }^{1,41}$ However, more recent studies noted a decreased incidence of PPE at 5\% when the reduced dosing of PLD was used, ie, $40 \mathrm{mg} / \mathrm{m}^{2}$ in the trial reported by Ferrandina. ${ }^{42}$ Outside of clinical trials, there are few data on the incidence of PPE in community practice. One report examining the association between PPE and body mass index (BMI) in 108 women receiving PLD for gynecologic malignancies recorded a $14 \%$ incidence of grade $3 \mathrm{PPE} .{ }^{50}$ Interestingly, there was no correlation between development of PPE and BMI in this analysis.

The pathophysiology of PPE has not been fully established, although it was speculated that increased excretion of PLD through sweat glands, which is enhanced by increased temperature may be a contributor. ${ }^{51}$ Several publications have presented risk factors for cutaneous toxicity induced by PLD. Strong evidence supports that overall amount of exposure to PLD correlates with toxicity. In a dose-escalation trial with single agent PLD, increases in exposure as measured by AUC, were associated with progressive increases in the rate of PPE. ${ }^{13}$

Several trials have investigated potential preventative regimens for PPE, including regional cooling, application of topical dimethyl sulfoxide (DMSO), and dose reduction as previously discussed. ${ }^{52}$ Regional cooling, achieved with the use of ice packs on extremities, was tested in 20 women, of which 17 underwent cooling procedures and 3 received routine care. The incidence of grade 3-4 PPE was $6 \%$ in the women undergoing cooling compared to $67 \%$ in the untreated group. While interesting, this report has limitations related to the small cohort size and the broad range of PLD doses administered ( 30 to $50 \mathrm{mg} / \mathrm{m}^{2}$ ). Given the known association between the amount of drug exposure and development of PPE, the conclusions of the study remain, at most, hypothesis generating. The use of topical DMSO as a treatment modality was reported in two patients, who experienced resolution of grade 3 PPE after four-times daily applications of topical DMSO ${ }^{53}$ Based on these limited data, it remains unclear whether there is a role for topical DMSO in the treatment of PPE. Other interventions used for the management of PPE include topical or systemic corticosteroids and pyridoxine (vitamin B6).$^{54}$ The role of pyridoxine in preventing handfoot syndrome in patients treated with PLD was examined prospectively in a placebo-controlled randomized trial led by the Case Cancer Center that recently completed accrual (not reported).

In addition to PPE, a variety of other cutaneous toxicities have been reported, including granular parakeratosis,

Table 2 Adverse events reported in phase III trials with pegylated liposomal doxorubicin (PLD)

\begin{tabular}{|c|c|c|c|c|}
\hline \multirow{2}{*}{$\begin{array}{l}\text { Study } \\
\text { Gordon et al 200I' }\end{array}$} & \multicolumn{2}{|c|}{ Grade 3-4 hematological toxicity } & \multicolumn{2}{|c|}{ Grade 3-4 nonhematological toxicity } \\
\hline & Neutropenia & $12 \%$ & PPE & $23 \%$ \\
\hline & Anemia & $5 \%$ & Stomatitis & $8.3 \%$ \\
\hline & Thrombocytopenia & $1 \%$ & & \\
\hline \multirow[t]{4}{*}{ Mutch et al $2007^{41}$} & Neutropenia & $18 \%$ & PPE & $10.4 \%$ \\
\hline & Febrile neutropenia & $4 \%$ & Mucositis & $3.1 \%$ \\
\hline & Anemia & $2 \%$ & & \\
\hline & Thrombocytopenia & $5 \%$ & & \\
\hline \multirow[t]{3}{*}{ Ferrandina et al $2008^{42}$} & Neutropenia & $6 \%$ & PPE & $5 \%$ \\
\hline & Anemia & $5 \%$ & Stomatitis & $3 \%$ \\
\hline & Thrombocytopenia & $0 \%$ & & \\
\hline \multirow[t]{3}{*}{ Pignata et al $2006^{83}$} & Neutropenia & $46 \%$ & PPE & $2 \%$ \\
\hline & Anemia & $16 \%$ & Stomatitis & 0 \\
\hline & Thrombocytopenia & $26 \%$ & & \\
\hline
\end{tabular}


radiation recall, and other skin manifestations of toxicity. $32,55,56$ Ageusia, or loss of sense of taste, was reported in one case and interestingly, resolved when treatment was switched to conventional DOX. ${ }^{57}$

\section{Ongoing development of PLD}

The strategy searching for synergy between PLD and other chemotherapeutics followed a similar course as the development of other combination regimens in oncology, with a large number of phase I trials reported, but only few combinations advancing to phase II and III development. In phase I work, PLD was combined with ifosphamide ${ }^{58}$ topotecan (oral ${ }^{59}$ or intravenous ${ }^{60-62}$ ), etoposide, ${ }^{63}$ taxanes, ${ }^{64-67}$ platinums, ${ }^{68-71}$ vinorelbine, ${ }^{24,72}$ gemcitabine, ${ }^{73,74}$ and capecitabine. ${ }^{75}$ These trials are reviewed in Table 3, which summarizes the relevant maximum tolerated dose toxicities. However, in spite of generally positive reports, only a few combinations have advanced to phase II evaluation. Table 4 presents important phase II combination regimens of PLD with topotecan, vinorelbine, platinums, and gemcitabine.

Table 3 Phase I combinations with pegylated liposomal doxorubicin (PLD)

\begin{tabular}{|c|c|c|c|}
\hline Agent combined & Maximum tolerated dose & Dose-limiting toxicities & Reference \\
\hline Ifosphamide & $\begin{array}{l}\text { PLD } 40 \mathrm{mg} / \mathrm{m}^{2} \text { day I } \\
\text { Ifos } 1500 \mathrm{mg} / \mathrm{m}^{2} / \text { day Days I-3 }\end{array}$ & Neutropenia & Bourgeois et al $2006^{58}$ \\
\hline Topotecan (po) & $\begin{array}{l}\text { PLD } 40 \mathrm{mg} / \mathrm{m}^{2} \text { day I } \\
\text { Topo } 1.53 \mathrm{mg} / \mathrm{m}^{2} / \text { day Days I-5 }\end{array}$ & Neutropenia & Rose et al $2008^{59}$ \\
\hline Topotecan & $\begin{array}{l}\text { PLD } 40 \mathrm{mg} / \mathrm{m}^{2} \text { Day } 4 \\
\text { Topo } 1.25 \mathrm{mg} / \mathrm{m}^{2} / \text { day Days I-3 }\end{array}$ & Neutropenia death & Garcia et al $2005^{60}$ \\
\hline Topotecan & $\begin{array}{l}\text { PLD } 40 \mathrm{mg} / \mathrm{m}^{2} \text { day I } \\
\text { Topo } 0.4 \mathrm{mg} / \mathrm{m}^{2} / \text { day Days I-14 }\end{array}$ & $\begin{array}{l}\text { Neutropenia } \\
\text { thrombocytopenia diarrhea }\end{array}$ & Mirchandani et al $2005^{62}$ \\
\hline Topotecan & $\begin{array}{l}\text { PLD } 35 \mathrm{mg} / \mathrm{m}^{2} \text { day I } \\
\text { Topo } 0.5 \mathrm{mg} / \mathrm{m}^{2} / \text { day Days I-5 }\end{array}$ & Neutropenia & Ghesquieres et al $2006^{61}$ \\
\hline Etoposide (po) & $\begin{array}{l}\text { PLD } 20 \mathrm{mg} / \mathrm{m}^{2} \text { day I } \\
\text { Topo } 50 \mathrm{mg} / \mathrm{m}^{2} / \text { day Days I-I } 5\end{array}$ & Hematologic not specified & Rose et al $2002^{63}$ \\
\hline Paclitaxel $^{b}$ & $\begin{array}{l}\text { PLD } 30 \mathrm{mg} / \mathrm{m}^{2} \text { day I } \\
\text { or } \\
\text { Pac } 90 \mathrm{mg} / \mathrm{m}^{2} \text { weekly } 4 / 6 \text { weeks } \\
\text { PLD } 35 \mathrm{mg} / \mathrm{m}^{2} \text { day I } \\
\text { Pac } 80 \mathrm{mg} / \mathrm{m}^{2} \text { weekly } 4 / 6 \text { weeks }\end{array}$ & Neutropenia PPE DVT & Briasoulis et al $2004^{65}$ \\
\hline Paclitaxel $^{b}$ & $\begin{array}{l}\text { PLD } 10 \mathrm{mg} / \mathrm{m}^{2} \text { Day I } \\
\text { Pac } 80 \mathrm{mg} / \mathrm{m}^{2} \text { weekly } 4 / 6 \text { weeks }\end{array}$ & Neutropenia diarrhea & Androulakis et al $2002^{64}$ \\
\hline Paclitaxel & $\begin{array}{l}\text { PLD I } 5 \mathrm{mg} / \mathrm{m}^{2} \text { day I } \\
\text { Pac III } 5 \mathrm{mg} / \mathrm{m}^{2} \text { days I and I } 5\end{array}$ & Neutropenia cardiac arrest & Mavroudis et al $2002^{67}$ \\
\hline Docetaxel & $\begin{array}{l}\text { PLD } 20 \mathrm{mg} / \mathrm{m}^{2} \text { days I and I5 } \\
\text { Doc } 40 \mathrm{mg} / \mathrm{m}^{2} \text { days I and I5 } \\
\text { Doc } 35 \mathrm{mg} / \mathrm{m}^{2} \text { days I and I5 } \\
\text { PLD } 20 \mathrm{mg} / \mathrm{m}^{2} \text { days I and I5 }\end{array}$ & $\begin{array}{l}\text { Skin toxicity } \\
\text { thrombocytopenia }\end{array}$ & Fracasso et al $2003^{66}$ \\
\hline Oxaliplatin ${ }^{\mathrm{a}}$ & $\begin{array}{l}\text { PLD } 40 \mathrm{mg} / \mathrm{m}^{2} \text { day I } \\
\text { Ox } 130 \mathrm{mg} / \mathrm{m}^{2} \text { day I }\end{array}$ & $\begin{array}{l}\text { Neutropenia } \\
\text { thrombocytopenia }\end{array}$ & Recchia et al $2003^{69}$ \\
\hline Carboplatin ${ }^{c}$ & $\begin{array}{l}\text { PLD } 35 \text { mg/m² day I } \\
\text { Carbo AUC } 5 \text { day I }\end{array}$ & $\begin{array}{l}\text { Neutropenia } \\
\text { thrombocytopenia }\end{array}$ & Goncalves et al $2003^{70}$ \\
\hline Cisplatin & $\begin{array}{l}\text { PLD } 50 \mathrm{mg} / \mathrm{m}^{2} \text { day } 2 \\
\text { Cis } 60 \mathrm{mg} / \mathrm{m}^{2} \text { day I }\end{array}$ & Neutropenia & Tas et al $2008^{71}$ \\
\hline Vinorelbine $^{\mathrm{a}}$ & $\begin{array}{l}\text { PLD } 30 \mathrm{mg} / \mathrm{m}^{2} \text { day I } \\
\text { Vin } 25 \mathrm{mg} / \mathrm{m}^{2} \text { days I and } 8\end{array}$ & Neutropenia & Tambaro et al $2003^{72}$ \\
\hline Gemcitabine & $\begin{array}{l}\text { PLD } 20 \mathrm{mg} / \mathrm{m}^{2} \text { days I and I5 } \\
\text { Gem } 2000 \mathrm{mg} / \mathrm{m}^{2} \text { Days I and I5 }\end{array}$ & Rash stomatitis & Fracasso et al $2002^{73}$ \\
\hline Capecitabine $(\mathrm{PO})^{\mathrm{a}}$ & $\begin{array}{l}\text { PLD } 40 \mathrm{mg} / \mathrm{m}^{2} \text { day I } \\
\text { Cap } 1500 \mathrm{mg} / \mathrm{m}^{2} \text { days I- } 14\end{array}$ & PPE asthenia & Maltezos et al $2005^{75}$ \\
\hline
\end{tabular}

a3-week cycle, b6-week cycle, '3- or 4-week cycle (if not specified, 4-week cycle).

Abbreviations: Carbo, carboplatin; Cis, cisplatin; Vin, vinorelbine; Pac, paclitaxel; Topo, topotecan; DVT, deep vein thrombosis; PPE, plantar palmar erythema. 
Table 4 Phase II combination regimens with pegylated liposomal doxorubicin (PLD) in ovarian cancer (OC)

\begin{tabular}{|c|c|c|c|c|}
\hline Combination & Study population & Results & $\begin{array}{l}\text { Grade 3-4 } \\
\text { toxicities }\end{array}$ & Reference \\
\hline 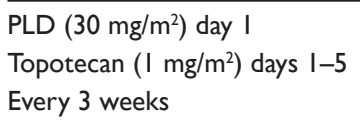 & $\begin{array}{l}\mathrm{N}=27 \\
\text { platinum refractory }\end{array}$ & $\begin{array}{l}\text { RR }=28 \% \\
\mathrm{SD}=44 \% \\
\text { TTP }=30 \text { weeks }\end{array}$ & Hematologic: 70\% & $\begin{array}{l}\text { Verhaar-Langereis } \\
\text { et al } 2006^{76}\end{array}$ \\
\hline $\begin{array}{l}\text { PLD }\left(30-35 \mathrm{mg} / \mathrm{m}^{2}\right) \text { day I } \\
\text { Oxaliplatin }\left(70 \mathrm{mg} / \mathrm{m}^{2}\right) \text { day } 2 \\
\text { Every } 4 \text { weeks }\end{array}$ & $\begin{array}{l}\mathrm{N}=43 \\
\text { platinum sensitive (29) } \\
\text { and refractory (14) }\end{array}$ & $\begin{array}{l}\mathrm{RR}=54 \% \\
\mathrm{SD}=29 \% \\
\mathrm{TTP}=10.2 \mathrm{mos}\end{array}$ & Neutropenia I2\% & Nicoletto et al $2006^{78}$ \\
\hline $\begin{array}{l}\text { PLD }\left(20 \mathrm{mg} / \mathrm{m}^{2}\right) \text { days I and } 2 \\
\text { Oxaliplatin }\left(60 \mathrm{mg} / \mathrm{m}^{2}\right) \text { day I } \\
\text { and } 2 \text {; every } 3 \text { weeks }\end{array}$ & $\begin{array}{l}\mathrm{N}=40 \\
\text { recurrent } \mathrm{OC}\end{array}$ & $\begin{array}{l}\mathrm{RR}=67 \% \\
\mathrm{SD}=25 \%\end{array}$ & Neutropenia $37 \%$ & Recchia et al $2007^{79}$ \\
\hline $\begin{array}{l}\text { PLD }\left(30 \mathrm{mg} / \mathrm{m}^{2}\right) \text { day I } \\
\text { Carboplatin (AUC 5) day I } \\
\text { Every } 4 \text { weeks }\end{array}$ & $\begin{array}{l}\mathrm{N}=104 \\
\text { recurrent } \mathrm{OC}\end{array}$ & $\begin{array}{l}\mathrm{RR}=62.5 \% \\
\mathrm{SD}=19 \% \\
\mathrm{TTP}=9.4 \mathrm{mos}\end{array}$ & Hematologic $51 \%$ & Ferrero et al $2007^{80}$ \\
\hline $\begin{array}{l}\text { PLD }\left(30 \mathrm{mg} / \mathrm{m}^{2}\right) \text { day I } \\
\text { Carboplatin (AUC 5) day I } \\
\text { Every } 4 \text { weeks }\end{array}$ & $\begin{array}{l}\mathrm{N}=3 \mathrm{I} \\
\text { platinum-sensitive }\end{array}$ & $\begin{array}{l}\mathrm{RR}=52 \% \\
\mathrm{TTP}=12 \mathrm{mos}\end{array}$ & Hematologic $81 \%$ & Alberts et al $2008^{81}$ \\
\hline $\begin{array}{l}\text { PLD }\left(40 \mathrm{mg} / \mathrm{m}^{2}\right) \text { day I } \\
\text { Carboplatin (AUC } 6) \text { day I } \\
\text { Every } 4 \text { weeks }\end{array}$ & $\begin{array}{l}\mathrm{N}=67 \\
\text { recurrent } \mathrm{OC}\end{array}$ & $\begin{array}{l}\mathrm{RR}=68 \% \\
\mathrm{TTP}=11.6 \mathrm{mos}\end{array}$ & $\begin{array}{l}\text { Neutropenia } 24 \% \\
\text { Fatigue } 12 \% \\
\text { Pain } 10 \%\end{array}$ & du Bois et al $2007^{82}$ \\
\hline $\begin{array}{l}\text { PLD }\left(30 \mathrm{mg} / \mathrm{m}^{2}\right) \text { day I } \\
\text { Vinorelbine }\left(30 \mathrm{mg} / \mathrm{m}^{2}\right) \text { day I } \\
\text { Every } 3 \text { weeks }\end{array}$ & $\begin{array}{l}\mathrm{N}=30 \\
\text { recurrent } \mathrm{OC}\end{array}$ & $\begin{array}{l}\mathrm{RR}=37 \% \\
\mathrm{SD}=10 \% \\
\text { TTP } 5.5 \mathrm{mos}\end{array}$ & $\begin{array}{l}\text { Neutropenia } 12 \% \\
\text { PPE } 7 \% \\
\text { Stomatitis } 7 \%\end{array}$ & Katsaros et al $2004^{77}$ \\
\hline $\begin{array}{l}\text { PLD }\left(30 \mathrm{mg} / \mathrm{m}^{2}\right) \text { day I } \\
\text { Gemcitabine }\left(1000 \mathrm{mg} / \mathrm{m}^{2}\right) \\
\text { Days I and } 8 \text { every } 3 \text { weeks }\end{array}$ & $\begin{array}{l}\mathrm{N}=67 \\
\text { recurrent } \mathrm{OC}\end{array}$ & $\begin{array}{l}\mathrm{RR}=34.3 \% \\
\mathrm{SD}=38.8 \% \\
\mathrm{TTP}=28 \text { weeks }\end{array}$ & $\begin{array}{l}\text { Neutropenia } 7 \% \\
\text { PPE 10\% } \\
\text { Stomatitis 10\% }\end{array}$ & D'Agostine et al $2003^{83}$ \\
\hline $\begin{array}{l}\text { PLD }\left(20 \mathrm{mg} / \mathrm{m}^{2}\right) \text { days I and I5 } \\
\text { Gemcitabine }\left(2000 \mathrm{mg} / \mathrm{m}^{2}\right) \\
\text { Days I and I } 5 \text { every } 4 \text { weeks }\end{array}$ & $\begin{array}{l}\mathrm{N}=18 \\
\text { platinum refractory }\end{array}$ & $\begin{array}{l}\mathrm{RR}=28 \% \\
\mathrm{TTP}=17 \mathrm{mos}\end{array}$ & Anemia $17 \%$ & Tas et al $2008^{74}$ \\
\hline
\end{tabular}

Notes: SD, stable disease; TTP, time to progression.

Abbreviation: $R R$, response rate.

In phase II combination therapy trials, PLD has been dosed at $30 \mathrm{mg} / \mathrm{m}^{2}$, which represents $60 \%$ of the FDA-approved PLD dose for OC. The combination with topotecan induced a RR of $28 \%$, but also marked grade 3 and 4 hematologic toxicity $(70 \%),{ }^{76}$ reducing enthusiasm for further development of this regimen. A natural combination for PLD was that with the platinum agents, oxaliplatin, and carboplatin. The combination with oxaliplatin was well tolerated, with grade 3 and 4 hematologic toxicities in the $20 \%$ to $30 \%$ range, and RR of $54 \%$ to $67 \% .^{78,79}$

At least 3 phase II trials have investigated PLD/ carboplatin combinations. Two trials combined PLD with carboplatin dosed to AUC 5 and reported RRs of 52\% to $62 \%{ }^{80,81}$ The third trial dosed carboplatin at an AUC of 6 and reported slightly higher RR of $68 \%{ }^{80-82} \mathrm{TTP}$ was similar, ranging between 9 and 12 months. This work, indicating interesting clinical activity of this combination in OC, led to its testing in phase III combination trials.
The Multicentre Italian Trials in Ovarian Cancer-2 (MITO-2) investigated PLD in combination with carboplatin in the first-line setting. In this trial, both arms include carboplatin given at an AUC of 5, with the control arm administering paclitaxel at $175 \mathrm{mg} / \mathrm{m}^{2}$, and the experimental arm using PLD at $30 \mathrm{mg} / \mathrm{m}^{2}$, both on a 21-day cycle. The trial completed enrollment in the last quarter of 2007 and initial results on 50 patients were reported the same year. The RR for patients receiving carboplatin/PLD was $68 \%$ and additional $20 \%$ of patients had stable disease. ${ }^{84}$ An interim safety analysis of MITO-2 was released in $2006^{85}$ and updated results were presented in $2009 .{ }^{86}$ Hematologic toxicities occurred frequently in both arms; grade 3-4 neutropenia in $43 \%$ of patients on the carboplatin/PLD arm and $49 \%$ of patients receiving carboplatin/paclitaxel (CT), grade 3-4 thrombocytopenia in $16 \%$ of patients receiving carboplatin/PLD vs $2 \%$ of patients on the standard arm $(P<0.001)$, and grade $3-4$ anemia in $10 \%$ of patients on the experimental arm versus $4 \%$ of patients receiving CT $(P<0.001)$. Nonhematologic 
toxicities included stomatitis and skin toxicity more common in the carboplatin/PLD arm $(20 \%$ each, $P<0.001)$ and neurotoxicity, alopecia, and diarrhea more frequent with the CT regimen. Although final results on OS and PFS are not yet available, early indicators of clinical activity in this trial show similar rates of RR ( $57 \%$ vs $59 \%$ ) and stable disease (31\% vs 29\%), ${ }^{86}$ suggesting that perhaps carboplatin/PLD may become an alternative treatment for upfront treatment of patients with OC. Other trials investigating the carboplatin/PLD combination include the ongoing Calypso phase III trial comparing CT to carboplatin/PLD in platinum-sensitive recurrent OC, run by the Gynecologic Cancer InterGroup (GCIG,), and the GOG protocol 182.

The Calypso trial, reported earlier in 2009, enrolled 976 patients with platinum-sensitive recurrent OC. ${ }^{87}$ Similar to the MITO-2 trial, rates of grade 3-4 stomatitis (13\%) and hand foot syndrome (11\%) were higher in the carboplatin/ PLD arm, but alopecia, carboplatin hypersensitivity reactions, and peripheral neurotoxicity were significantly lower compared to those induced by the CT regimen. The median PFS was 11.3 months for carboplatin/PLD compared to 9.4 months for the standard regimen $(P<0.001)$, positioning this regimen as a viable and less toxic alternative to $\mathrm{CT}$ in the setting of first platinum-sensitive OC recurrence.

In protocol GOG 182/ICON5, the combination carboplatin with paclitaxel (CT) and PLD was tested against the standard adjuvant regimen $\mathrm{CT}$ and 3 other regimens incorporating either topotecan or gemcitabine along with CT. In this arm, PLD was given at $30 \mathrm{mg} / \mathrm{m}^{2}$ every other cycle along with standard doses of CT. Of 862 patients randomized to this regimen, 658 completed 8 cycles of therapy. ${ }^{88}$ The median PFS of patients treated with CT/PLD was 16.4 months and the median OS was 42.8 months, not different from the standard arm or from the other 3 experimental regimens, suggesting that addition of PLD to the CT regimen does not improve outcome. Significant toxicities included grade 4 neutropenia $(70 \%)$, grade 3-4 thrombocytopenia (38\%), grade 3-4 anemia (20\%), higher than observed with the standard arm. However rates of pulmonary, hepatic, gastrointestinal toxicities and neuropathy were not significantly increased by the addition of PLD to the CT regimen.

The mild toxicity profile of PLD renders liposomal doxorubicin an ideal partner for combination regimens. At present, PLD is currently being investigated in combination with biological agents targeting tumor vasculature or other biological mechanisms relevant to tumor growth. For instance, PLD is being studied in combination with volocixumab, an antibody against $\alpha 5 \beta 1$ integrin complex
(ClinicalTrials.gov identifier: NCT00635193); bevacizumab, an anti-VEGF antibody (ClinicalTrials.gov identifier: NCT00846612); AMG386, an angiopoietin inhibitor (ClinicalTrials.gov identifier: NCT00770536), panitumomab, an EGFR directed antibody (ClinicalTrials.gov identifier: NCT00861120); and others.

Combinations of PLD with novel cytotoxics included those with canfosfamide, EC145, a folate receptor targeted cytotoxic agent, and trabectidin. A phase III trial testing PLD in combination with trabectidin compared to PLD in 650 women with recurrent OC has completed accrual, but has not yet been reported. Likewise, the combination PLD and canfosfamide has been compared to PLD as a single agent in a phase III trial enrolling 240 patients (unpublished).

\section{Conclusions}

In conclusion, the liposomal formulation of doxorubicin alters favorably the toxicity profile of the parent drug, rendering PLD an easily tolerable agent. Due to the liposomal encapsulation, the agent is better delivered to tumor sites enabling enhanced exposure of cancer cells to DOX. Based on these properties, PLD has been investigated and found to be active in OC, leading to its approval for second-line therapy. Its testing in front-line regimens along with CT failed to improve survival. At the current time, PLD administered as a single agent is considered a very effective and tolerable option for second-line treatment of recurrent OC and therefore PLD is used as the comparator arm in many studies testing novel agents for recurrent OC. Its mild toxicity profile makes it an ideal partner for combination regimens with other cytotoxics, and more recently with biological agents, particularly with anti-angiogenic therapies. The recent results of the MITO-2 and Calypso trials suggest that the combination with carboplatin is an effective and nontoxic alternative for patients with platinum-sensitive OC. Pending results of trials testing PLD in combination with other biological agents, particularly anti-angiogenic drugs, may further strengthen its role in the treatment of recurrent OC.

\section{Disclosures}

The authors disclose no conflicts of interest.

\section{References}

1. Gordon AN, Fleagle JT, Guthrie D, et al. Recurrent epithelial ovarian carcinoma: a randomized phase III study of pegylated liposomal doxorubicin versus topotecan. J Clin Oncol. 2001;19(14):3312-3322.

2. Ziemer M, Goetze S, Kaatz M, Elsner P. Chemotherapy-induced toxic erythema under treatment with pegylated liposomal doxorubicin: No restriction to palms and soles. J Am Acad Dermatol. 2008;58(2 Suppl): S44-S46. 
3. Uyar D, Kulp B, Peterson G, et al. Cardiac safety profile of prolonged ( $\geq 6$ cycles) pegylated liposomal doxorubicin administration in patients with gynecologic malignancies. Gynecol Oncol. 2004;94(1): $147-151$.

4. Gregoriadis G. Targeting of drugs: implications in medicine. Lancet. 1981;2(8240):241-246.

5. Gabizon A. Tailoring liposomes for cancer drug delivery: from the bench to the clinic. Ann Biol Clin (Paris). 1993;51(9):811-813.

6. Kaye SB, Richardson VJ. Potential of liposomes as drug-carriers in cancer chemotherapy: a review. Cancer Chemother Pharmacol. 1979;3(2):81-85.

7. Gabizon A, Dagan A, Goren D, Barenholz Y, Fuks Z. Liposomes as in vivo carriers of adriamycin: reduced cardiac uptake and preserved antitumor activity in mice. Cancer Res. 1982;42(11): 4734-4739.

8. Gabizon A, Papahadjopoulos D. Liposome formulations with prolonged circulation time in blood and enhanced uptake by tumors. Proc Natl Acad Sci U S A. 1988;85(18):6949-6953.

9. Poste G, Bucana C, Raz A, et al. Analysis of the fate of systemically administered liposomes and implications for their use in drug delivery. Cancer Res. 1982;42(4):1412-1422.

10. Gabizon A, Goren D, Cohen R, Barenholz Y. Development of liposomal anthracyclines: from basics to clinical applications. J Control Release. 1998;53(1-3):275-279.

11. Gabizon A, Shmeeda H, Barenholz Y. Pharmacokinetics of pegylated liposomal Doxorubicin: review of animal and human studies. Clin Pharmacokinet. 2003;42(5):419-436.

12. Harrington KJ, Rowlinson-Busza G, Syrigos KN, et al. Pegylated liposomes have potential as vehicles for intratumoral and subcutaneous drug delivery. Clin Cancer Res. 2000;6(6):2528-2537.

13. Hong RL, Huang CJ, Tseng YL, et al. Direct comparison of liposomal doxorubicin with or without polyethylene glycol coating in C-26 tumorbearing mice: is surface coating with polyethylene glycol beneficial? Clin Cancer Res. 1999;5(11):3645-3652.

14. Parr MJ, Masin D, Cullis PR, Bally MB. Accumulation of liposomal lipid and encapsulated doxorubicin in murine Lewis lung carcinoma: the lack of beneficial effects by coating liposomes with poly(ethylene glycol). J Pharmacol Exp Ther. 1997;280(3):1319-1327.

15. Lu WL, Qi XR, Zhang Q, et al. A pegylated liposomal platform: pharmacokinetics, pharmacodynamics, and toxicity in mice using doxorubicin as a model drug. J Pharmacol Sci. 2004;95(3): 381-389.

16. Gabizon A, Catane R, Uziely B, et al. Prolonged circulation time and enhanced accumulation in malignant exudates of doxorubicin encapsulated in polyethylene-glycol coated liposomes. Cancer Res. 1994;54(4):987-992.

17. Goren D, Gabizon A, Barenholz Y. The influence of physical characteristics of liposomes containing doxorubicin on their pharmacological behavior. Biochim Biophys Acta. 1990;1029(2): 285-294.

18. Charrois GJ, Allen TM. Drug release rate influences the pharmacokinetics, biodistribution, therapeutic activity, and toxicity of pegylated liposomal doxorubicin formulations in murine breast cancer. Biochim Biophys Acta. 2004;1663(1-2):167-177.

19. Freyer G, Tranchand B, Ligneau B, et al. Population pharmacokinetics of doxorubicin, etoposide and ifosfamide in small cell lung cancer patients: results of a multicentre study. British Journal of Clinical Pharmacology. 2000;50(4):315-324.

20. Speth PA, van Hoesel QG, Haanen C. Clinical pharmacokinetics of doxorubicin. Clin Pharmacokinet. 1988;15(1):15-31.

21. Li Y, Finkel KW, Hu W, et al. Pegylated liposomal doxorubicin treatment in recurrent gynecologic cancer patients with renal dysfunction. Gynecol Oncol. 2007;106(2):375-380.

22. Ishida T, Atobe K, Wang X, Kiwada H. Accelerated blood clearance of PEGylated liposomes upon repeated injections: effect of doxorubicinencapsulation and high-dose first injection. $J$ Control Release. 2006;115(3):251-258.
23. Gabizon A, Isacson R, Rosengarten O, et al. An open-label study to evaluate dose and cycle dependence of the pharmacokinetics of pegylated liposomal doxorubicin. Cancer Chemother Pharmacol. 2008;61(4):695-702.

24. Cattel L, Passera R, Katsaros D, et al. Pegylated liposomal doxorubicin and vinorelbine in recurrent ovarian carcinoma: a pharmacokinetic study on alternate administration sequences. Anticancer Res. 2006;26(1B):745-750.

25. Sells RA, Owen RR, New RR, Gilmore IT. Reduction in toxicity of doxorubicin by liposomal entrapment. Lancet. 1987;2(8559): 624-625.

26. Alberts DS, Muggia FM, Carmichael J, et al. Efficacy and safety of liposomal anthracyclines in phase I/II clinical trials. Semin Oncol. 2004;31(6 Suppl 13):53-90.

27. Gabizon A, Peretz T, Sulkes A, et al. Systemic administration of doxorubicin-containing liposomes in cancer patients: a phase I study. Eur J Cancer Clin Oncol. 1989;25(12):1795-1803.

28. Campos S, Penson R, MacNeill K, et al. A Retrospective Analysis of the Clinical Utility of Doxil in Recurrent Ovarian Cancer (ROC). Proc Am Soc Clin Oncol. 1999:Abstract 1434

29. Israel VP, Garcia AA, Roman L, et al. Phase II study of liposomal doxorubicin in advanced gynecologic cancers. Gynecol Oncol. 2000;78(2):143-147.

30. Uziely B, Jeffers S, Isacson R, et al. Liposomal doxorubicin: antitumor activity and unique toxicities during two complementary phase I studies. J Clin Oncol. 1995;13(7):1777-1785.

31. Campos SM, Penson RT, Mays AR, et al. The clinical utility of liposomal doxorubicin in recurrent ovarian cancer. Gynecol Oncol. 2001;81(2):206-212.

32. Kim RJ, Peterson G, Kulp B, Zanotti KM, Markman M. Skin toxicity associated with pegylated liposomal doxorubicin $\left(40 \mathrm{mg} / \mathrm{m}^{2}\right)$ in the treatment of gynecologic cancers. Gynecol Oncol. 2005;97(2): 374-378.

33. Markman M, Kennedy A, Webster K, et al. Phase 2 trial of liposomal doxorubicin $\left(40 \mathrm{mg} / \mathrm{m}^{2}\right)$ in platinum/paclitaxel-refractory ovarian and fallopian tube cancers and primary carcinoma of the peritoneum. Gynecol Oncol. 2000;78(3 Pt 1):369-372.

34. Oskay-Oezcelik G, Koensgen D, Hindenburg HJ, et al. Biweekly pegylated liposomal doxorubicin as second-line treatment in patients with relapsed ovarian cancer after failure of platinum and paclitaxel: results from a multi-center phase II study of the NOGGO. Anticancer Res. 2008;28(2B):1329-1334.

35. Sehouli J, Oskay-Ozcelik G, Kühne J, et al. Biweekly pegylated liposomal doxorubicin in patients with relapsed ovarian cancer: results of a multicenter phase-II trial. Ann. Oncol. 2006;17(6):957-961.

36. Rustin GJS, Bast RC, Kelloff GJ, et al. Use of CA-125 in clinical trial evaluation of new therapeutic drugs for ovarian cancer. Clin. Cancer Res. 2004;10(11):3919-3926.

37. Sabbatini P, Mooney D, Iasonos A, et al. Early CA-125 fluctuations in patients with recurrent ovarian cancer receiving chemotherapy. Int J Gynecol Cancer. 2007;17(3):589-594.

38. Coleman RL, Gordon A, Barter J, et al. Early changes in CA125 after treatment with pegylated liposomal doxorubicin or topotecan do not always reflect best response in recurrent ovarian cancer patients. Oncologist. 2007;12(1):72-78.

39. Gossner G, Coleman RL, Mutch DG, et al. CA-125 response in patients with recurrent ovarian or primary peritoneal cancer treated with pegylated liposomal doxorubicin or topotecan. Gynecol Oncol. 2006;103(1):212-218.

40. Gordon AN, Tonda M, Sun S, Rackoff W. Long-term survival advantage for women treated with pegylated liposomal doxorubicin compared with topotecan in a phase 3 randomized study of recurrent and refractory epithelial ovarian cancer. Gynecol Oncol. 2004;95(1):1-8.

41. Mutch DG, Orlando M, Goss T, et al. Randomized phase III trial of gemcitabine compared with pegylated liposomal doxorubicin in patients with platinum-resistant ovarian cancer. J Clin Oncol. 2007; 25(19):2811-2818. 
42. Ferrandina G, Ludovisi M, Lorusso D, et al. Phase III trial of gemcitabine compared with pegylated liposomal doxorubicin in progressive or recurrent ovarian cancer. J Clin Oncol. 2008;26(6):890-896.

43. Therasse P, Arbuck SG, Eisenhauer EA, et al. New guidelines to evaluate the response to treatment in solid tumors. European Organization for Research and Treatment of Cancer, National Cancer Institute of the United States, National Cancer Institute of Canada. J Natl Cancer Inst. 2000;92(3):205-216.

44. Von Hoff DD, Layard MW, Basa P, et al. Risk factors for doxorubicininduced congestive heart failure. Ann Intern Med. 1979;91(5):710-717.

45. Gabizon AA, Lyass O, Berry GJ, Wildgust M. Cardiac safety of pegylated liposomal doxorubicin (Doxil/Caelyx) demonstrated by endomyocardial biopsy in patients with advanced malignancies. Cancer Invest. 2004;22(5):663-669.

46. Yildirim Y, Gultekin E, Avci ME, et al. Cardiac safety profile of pegylated liposomal doxorubicin reaching or exceeding lifetime cumulative doses of $550 \mathrm{mg} / \mathrm{m}^{2}$ in patients with recurrent ovarian and peritoneal cancer. Int J Gynecol Cancer. 2008;18(2):223-227.

47. Ferrandina G, Paris I, Ludovisi M, et al. Gemcitabine and liposomal doxorubicin in the salvage treatment of ovarian cancer: updated results and long-term survival. Gynecol Oncol. 2005;98(2): 267-273.

48. Lokich JJ, Moore C. Chemotherapy-associated palmar-plantar erythrodysesthesia syndrome. Ann Intern Med. 1984;101(6):798-799.

49. Lyass O, Uziely B, Ben-Yosef R, et al. Correlation of toxicity with pharmacokinetics of pegylated liposomal doxorubicin (Doxil) in metastatic breast carcinoma. Cancer. 2000;89(5):1037-1047.

50. Gordinier ME, Dizon DS, Fleming EL, et al. Elevated body mass index does not increase the risk of palmar-plantar erythrodysesthesia in patients receiving pegylated liposomal doxorubicin. Gynecol Oncol. 2006;103(1):72-74.

51. Lorusso D, Di Stefano A, Carone V, et al. Pegylated liposomal doxorubicin-related palmar-plantar erythrodysesthesia ('hand-foot' syndrome). Ann Oncol. 2007;18(7):1159-1164.

52. Molpus KL, Anderson LB, Craig CL, Puleo JG. The effect of regional cooling on toxicity associated with intravenous infusion of pegylated liposomal doxorubicin in recurrent ovarian carcinoma. Gynecol Oncol. 2004;93(2):513-516

53. Lopez AM, Wallace L, Dorr RT, et al. Topical DMSO treatment for pegylated liposomal doxorubicin-induced palmar-plantar erythrodysesthesia. Cancer Chemother Pharmacol. 1999;44(4):303-306.

54. Nagore E, Insa A, Sanmartín O. Antineoplastic therapy-induced palmar plantar erythrodysesthesia ('hand-foot') syndrome. Incidence, recognition and management. Am J Clin Dermatol. 2000;1(4):225-234.

55. Jaconelli L, Doebelin B, Kanitakis J, et al. Granular parakeratosis in a patient treated with liposomal doxorubicin for ovarian carcinoma. J Am Acad Dermatol. 2008;58(5 Suppl 1):S84-S87.

56. Mangana J, Zipser MC, Conrad C, et al. Skin problems associated with pegylated liposomal doxorubicin-more than palmoplantar erythrodysesthesia syndrome. Eur J Dermatol. 2008;18(5):566-570.

57. Kiewe P, Jovanovic S, Thiel E, Korfel A. Reversible ageusia after chemotherapy with pegylated liposomal doxorubicin. Ann Pharmacother. 2004;38(7-8):1212-1214.

58. Bourgeois H, Joly F, Pujade-Lauraine E, et al. Phase I study of pegylated liposomal doxorubicin in combination with ifosfamide in pretreated ovarian cancer patients. Am J Clin Oncol. 2006;29(4):399-404.

59. Rose PG, Smrekar M, Haba P, Fusco N, Rodriguez M. A phase I study of oral topotecan and pegylated liposomal doxorubicin (doxil) in platinum-resistant ovarian and peritoneal cancer. Am J Clin Oncol 2008;31(5):476-480.

60. Garcia AA, Roman L, Muderspach L, et al. Phase I clinical trial of topotecan and pegylated liposomal doxorubicin. Cancer Invest. 2005;23(8):665-670.

61. Ghesquieres H, Faivre S, Djafari L, et al. Phase I dose escalation study of pegylated liposomal doxorubicin (Caelyx) in combination with topotecan in patients with advanced malignancies. Invest New Drugs. 2006;24(5):413-421.
62. Mirchandani D, Hochster H, Hamilton A, et al. Phase I study of combined pegylated liposomal doxorubicin with protracted daily topotecan for ovarian cancer. Clin Cancer Res. 2005;11(16):5912-5919.

63. Rose PG, Rodriguez M, Walker J, et al. A phase I trial of prolonged oral etoposide and liposomal doxorubicin in ovarian, peritoneal, and tubal carcinoma: a gynecologic oncology group study. Gynecol Oncol. 2002;85(1):136-139.

64. Androulakis N, Kouroussis C, Mavroudis D, et al. Phase I study of weekly paclitaxel and liposomal doxorubicin in patients with advanced solid tumours. Eur J Cancer. 2002;38(15):1992-1997.

65. Briasoulis E, Pentheroudakis G, Karavasilis V, et al. Weekly paclitaxel combined with pegylated liposomal doxorubicin (CaelyxTM) given every 4 weeks: dose-finding and pharmacokinetic study in patients with advanced solid tumors. Ann Oncol. 2004;15(10):1566-1573.

66. Fracasso PM, Rodriguez LC, Herzog TJ, et al. Phase I dose and sequencing study of pegylated liposomal doxorubicin and docetaxel in patients with advanced malignancies. Cancer. 2003;98(3):610-617.

67. Mavroudis D, Kouroussis C, Kakolyris S, et al. Phase I study of paclitaxel (taxol) and pegylated liposomal doxorubicin (caelyx) administered every 2 weeks in patients with advanced solid tumors. Oncology. 2002;62(3):216-222.

68. du Bois A, Burges A, Meier W, et al. Pegylated liposomal doxorubicin and carboplatin in advanced gynecologic tumors: a prospective phase I/II study of the Arbeitsgemeinschaft Gynaekologische Onkologie Studiengruppe Ovarialkarzinom (AGO-OVAR). Ann Oncol. 2006;17(1):93-96.

69. Recchia F, De Filippis S, Saggio G, et al. Phase I study of liposomal doxorubicin and oxaliplatin as salvage chemotherapy in advanced ovarian cancer. Anticancer Drugs. 2003;14(8):633-638.

70. Goncalves A, Braud AC, Viret F, et al. Phase I study of pegylated liposomal doxorubicin (Caelyx) in combination with carboplatin in patients with advanced solid tumors. Anticancer Res. 2003;23(4):3543-3548.

71. Tas F, Derin D, Guney N, Aydiner A, Topuz E. Chemotherapy with pegylated liposomal doxorubicin and cisplatin in recurrent platinumsensitive epithelial ovarian cancer. Int J Clin Oncol. 2008;13(4):330-334.

72. Tambaro R, Greggi S, Iaffaioli RV, et al. An escalating dose finding study of liposomal doxorubicin and vinorelbine for the treatment of refractory or resistant epithelial ovarian cancer. Ann Oncol. 2003;14(9):1406-1411.

73. Fracasso PM, Blum KA, Tan BR, et al. Phase I study of pegylated liposomal doxorubicin and gemcitabine in patients with advanced malignancies. Cancer. 2002;95(10):2223-2229.

74. Tas F, Guney N, Derin D, Aydiner A, Topuz E. A pilot study evaluating the efficacy and toxicity of biweekly gemcitabine and pegylated liposomal doxorubicin in recurrent platinum-resistant epithelial ovarian cancer. Int J Clin Oncol. 2008;13(2):156-160.

75. Maltezos E, Amarantidis K, Trichas M, et al. A dose escalation study of pegylated liposomal Doxorubicin (caelyx) in combination with capecitabine (xeloda) in patients with refractory solid tumors. Oncology. 2005;69(6):463-469.

76. Verhaar-Langereis M, Karakus A, van Eijkeren M, Voest E, Witteveen E. Phase II study of the combination of pegylated liposomal doxorubicin and topotecan in platinum-resistant ovarian cancer. Int $J$ Gynecol Cancer. 2006;16(1):65-70.

77. Katsaros D, Oletti MV, Rigault de la Longrais IA, et al. Clinical and pharmacokinetic phase II study of pegylated liposomal doxorubicin and vinorelbine in heavily pretreated recurrent ovarian carcinoma. Ann Oncol. 2005;16(2):300-306.

78. Nicoletto MO, Falci C, Pianalto D, et al. Phase II study of pegylated liposomal doxorubicin and oxaliplatin in relapsed advanced ovarian cancer. Gynecol Oncol. 2006;100(2):318-323.

79. Recchia F, Saggio G, Amiconi G, et al. A multicenter phase II study of pegylated liposomal doxorubicin and oxaliplatin in recurrent ovarian cancer. Gynecol Oncol. 2007;106(1):164-169.

80. Ferrero JM, Weber B, Geay JF, et al. Second-line chemotherapy with pegylated liposomal doxorubicin and carboplatin is highly effective in patients with advanced ovarian cancer in late relapse: a GINECO phase II trial. Ann Oncol. 2007;18(2):263-268. 
81. Alberts DS, Liu PY, Wilczynski SP, et al. Randomized trial of pegylated liposomal doxorubicin (PLD) plus carboplatin versus carboplatin in platinum-sensitive (PS) patients with recurrent epithelial ovarian or peritoneal carcinoma after failure of initial platinum-based chemotherapy (Southwest Oncology Group Protocol S0200). Gynecol Oncol. 2008;108(1):90-94.

82. du Bois A, Pfisterer J, Burchardi N, et al. Combination therapy with pegylated liposomal doxorubicin and carboplatin in gynecologic malignancies: a prospective phase II study of the Arbeitsgemeinschaft Gynaekologische Onkologie Studiengruppe Ovarialkarzinom (AGO-OVAR) and Kommission Uterus (AGO-K-Ut). Gynecol Oncol. 2007;107(3):518-525.

83. D'Agostino G, Ferrandina G, Ludovisi M, et al. Phase II study of liposomal doxorubicin and gemcitabine in the salvage treatment of ovarian cancer. Br J Cancer. 2003;89(7):1180-1184.

84. Pignata S, Scambia G, Savarese A, et al. Carboplatin and pegylated liposomal doxorubicin for advanced ovarian cancer: preliminary activity results of the MITO-2 phase III trial. Oncology. 2009;76(1):49-54.
85. Pignata S, Scambia G, Savarese A, et al. Safety of a 3-weekly schedule of carboplatin plus pegylated liposomal doxorubicin as first line chemotherapy in patients with ovarian cancer: preliminary results of the MITO-2 randomized trial. BMC Cancer. 2006;6:202.

86. Pignata S, Scambia G, Savarese A, et al. Carboplatin plus paclitaxel (CP) versus carboplatin plus stealth liposomal doxorubicin (CLD) in patients with advanced ovarian cancer (AOC): Activity and safety results of the MITO-2 randomized multicenter trial. J Clin Oncol. 2009;27(18s):suppl; abstr LBA5508.

87. Pujade-Lauraine E, Mahner S, Kaern J, et al. A randomized, phase III study of carboplatin and pegylated liposomal doxorubicin versus carboplatin and paclitaxel in relapsed platinum-sensitive ovarian cancer (OC): CALYPSO study of the Gynecologic Cancer Intergroup (GCIG). J Clin Oncol. 2009;27(18s):suppl; abstr LBA5509.

88. Bookman MA, Brady MF, McGuire WP, et al. Evaluation of new platinum-based treatment regimens in advanced-stage ovarian cancer: a Phase III Trial of the Gynecologic Cancer Intergroup. J Clin Oncol. 2009;27(9):1419-1425.
Therapeutics and Clinical Risk Management

\section{Publish your work in this journal}

Therapeutics and Clinical Risk Management is an international, peerreviewed journal of clinical therapeutics and risk management, focusing on concise rapid reporting of clinical studies in all therapeutic areas outcomes, safety, and programs for the effective, safe, and sustained use of medicines. This journal is indexed on PubMed Central, CAS,

\section{Dovepress}

EMBase, Scopus and the Elsevier Bibliographic databases. The manuscript management system is completely online and includes a very quick and fair peer-review system, which is all easy to use. Visit http://www.dovepress.com/testimonials.php to read real quotes from published authors. 